JURNAL ILMIAH ELEKTRONIKA DAN KOMPUTER, Vol.14, No.2, Desember 2021, pp. 350 - 360

p-ISSN : 1907-0012 (print)

e-ISSN : 2714-5417 (online)

http://journal.stekom.ac.id/index.php/elkom

\title{
Pemetaan Wilayah Area Marketing Dealer X di Kabupaten Demak untuk Peningkatan Rencana Strategis Pemasaran
}

\author{
Wawan Susanto ${ }^{1}$, Haikal Nur R.A ${ }^{2}$, Sigit Umar Anggono ${ }^{3}$ \\ ${ }^{1}$ Universitas Kristen Satya Wacana \\ Jl. Dr. O. Notohamidjojo No. 1-10, Blotongan, Kota Salatiga, e-mail: livewawan@gmail.com \\ ${ }^{2}$ Universitas Kristen Satya Wacana \\ Jl. Dr. O. Notohamidjojo No. 1-10, Blotongan, Kota Salatiga, e-mail: haikalachaqie@gmail.com \\ ${ }^{3}$ Universitas Kristen Satya Wacana \\ J1. Dr. O. Notohamidjojo No. 1-10, Blotongan, Kota Salatiga, e-mail: mineart.design@gmail.com
}

\section{ARTICLE INFO}

Article history:

Received 17 November 2021

Received in revised form 19 November 2021

Accepted 19 November 2021

Available online 1 Desember 2021

\section{ABSTRACT}

Mapping the area of marketing area into one of the tools that can be used to describe a business activity for knowing the right target in the implementation in a particular work area. This research tries to design the mapping area of marketing area, is expected with this research can improve the appropriate marketing strategic plan accordingly target. So it can help the management of Dealer $X$ demak branch in determining its marketing policy. In This mapping uses QGis software for mapping. The result of this research is output map that can used for marketing department considerations to map out existing marketing areas in the region determined. ABSTRAK DI TULIS BAHASA INGGRIS

Keywords: mapping, marketing, marketing strategic plan improvement, Demak regency, QGis

\begin{abstract}
Abstrak
Pemetaan wilayah area marketing menjadi salah satu alat bantu yang bisa digunakan untuk menjabarkan suatu kegiatan bisnis untuk mengetahui sasaran yang tepat dalam pelaksanaan di suatu area kerja tertentu. Penelitian ini mencoba untuk merancang pemetaan wilayah area pemasaran, diharapkan dengan adanya penelitian ini bisa meningkatkan rencana strategis pemasaran yang tepat sesuai sasaran. Sehingga dapat membantu pihak manajemen Dealer X cabang demak dalam menentukan kebijakan pemasarannya. Dalam penbuatan pemetaan ini menggunakan software QGis untuk pemetaannya. Hasil penelitian ini berupa output peta yang bisa digunakan untuk pertimbangan department pemasaran guna memetakan area-area marketing yang ada diwilayah yang telah ditentukan.
\end{abstract}

Kata Kunci : pemetaan, pemasaran, peningkatan rencana strategis pemasaran, kabupaten demak, QGis.

\section{Pendahuluan}

Setiap dealer selalu memiliki tujuan yang ingin dicapai, tujuan tersebut diantaranya adalah mendapatkan keuntungan yang besar sehingga dapat membantu tercapainya tujuan - tujuan yang lain yang dimiliki oleh dealer. Salah satu tujuan utama yaitu memaksimalkan marketing untuk berupaya mencapai target yang telah ditentukan. Penyusunan Received November 17, 2021; Revised November 19, 2021; Accepted November 19, 2021 
strategi dan program pemasaran akan menjadi faktor kunci dalam keberhasilan pelaksanaan rencana strategis di bidang pemasaran khususnya dalam penelitian ini di wilayah kabupaten demak. untuk mecapai hal tersebut dibutuhkan adanya pertimbangan secara sistematis dan terukur. Pertimbangan tersebut akan menghasilkan alur dan prioritas pelaksanaan program secara berjenjang, mengingat keterbatasan sumber daya dan dana.

Permasalahan yang terjadi dalam dealer $\mathrm{X}$ ini adalah sering terjadinya penumpukan ataupun benturan penjualan antar sales yang akhinya berujung pada perebutan customers karena tidak terbaginya pemetaan wilayah kerja mereka. Perebutan customers ini juga mengakibatkan dampak lain yang sekiranya akan membuat gesekan antar sales yang semakin tidak sehat. Dari gesekan ini kadang dimafaatkan kompertitor marketing dealer lain untuk merebut pasar penjualan di wilayah mereka, sehingga kehilangan customers adalah menjadi sesuatu hal yang masif. Dengan penelitian mengenai pemetaan ini diharapkan sales dapat bekerja fokus untuk membangun dan mengembangkan wilayahnya agar dapat mempertahankan brand mereka dari panggung penjualan unit mobil dalam wilayah kerja kabupaten Demak. Permasalahan lain yang sekiranya dapat kita angkat, salah satunya adalah pengembangan wilayah kabupaten Demak yang masih berpotensi untuk dikembangkan menjadi wilayah dengan penjualan unit mobil yang baik dan menguntungkan tentunya.

Rencana Strategis adalah rangkaian pemikiran strategis terhadap suatu usulan penyelesaian masalah yang didasari oleh tujuan yang terukur. Tetapi tujuan yang terukur tersebut harus dijabarkan dalam perumusan program dan kegiatan yang terarah, tersekmentasi atas batasan dan ukuran yang jelas. Jikalau ukuran batasan tersebut tidak jelas, maka rencana tinggalah rencana yang tidak berujung pada penyelesaian.

Dealer X merupakan dealer resmi dan distributor resmi Toyota yang ada di wilayah jawa tengah. Seiring dengan meningkatnya penjualan tiap tahunya maka dibukalah cabang di beberapa kota dan kabupaten di wilayah jawa tengah, salah satunya adalah di kabupaten demak. Berbagai upaya telah dilakukan untuk meningkatkan penjualan baik dengan melalui event pemasaran, promosi pada tempat-tempat yang berpotensi sampai dengan perekrutan karyawan dibidang marketing untuk mendongkrak penjualan di wilayah kabupaten demak.

Kabupaten Demak memiliki potensi ekonomi dan corak pertumbuhan ekonomi yang berbeda dengan daerah lain. Oleh karenya perencanaan pembangunan ekonomi suatu daerah harus memperhatikan potensi daerah itu sendiri. Sebagai daerah otonom, kabupaten demak mempunyai potensi cukup besar untuk dikembangkan. Tak kalah dengan sector pertanian, sector non pertanian pun memiliki andil besar dalam menggerakkan motor perekonomian kabupaten demak. Kondisi ini merupakan salah satu peluang bagi pelaku usaha khususnya dalam hal ini dealer $\mathrm{X}$ demak untuk bertindak dan berinisiatif melalui penyiapan rencana strategis pemasaran yang nantinya dijadikan acuan dalam penyusunan rencana kerja bagian department pemasaran. Dikarenakan dalam hal ini dealer X cabang demak baru dibuka pada awal tahun 2018 ini, maka diperlukan rencana-rencana peningkatan strategis pemasaran seperti pada penelitian ini.

\section{Kajian Penelitian}

Pada penelitian terdahulu "model sales territory management "cluster war" sebagai bentuk strategi pemasaran pada pt. telkomsel sub branch malang" penelitian ini bertujuan untuk menjelaskan aplikasi model sales territory management (STM) "Cluster War" pada PT. Telkomsel Sub Branch Malang yang mencangkup pra pelaksanaan dan pelaksanaan STM. Hasil penelitian ini menggambarkan bahwa sales territory management sebagai strategi pemasaran. Kesimpulan dari penelitian ini adalah bahwa perencanaan sales territory management pada PT. Telkomsel menghasilkan output yang dapat diperoleh dari kegiatan sales Territority Management meliputi : peluang mengidentifikasi bisnis, optimalisasi penyebaran sumberdaya, focus pada

Pemetaan Wilayah Area Marketing Dealer X di Kabupaten Demak untuk Peningkatan Rencana Strategis Pemasaran (Wawan Susanto) 
prioritas kunci, mengukur kinerja perusahaan, pengelolaan hasil salesterritory kontrol yang lebih efisien[1].

Pada penelitian terdahulu "Digitalisasi Pemetaan UKM tenun Garut Berbasis Sistem Informasi Geografis sebagai Media Komunikasi dan Pemasaran Produk Lokal" penelitian ini bertujuan untuk membantu mengatasi permasalahan dalam hal pemasaran dan sekaligus turut serta melestarikan kerajinan industri kreatif Garut. Hasil penelitian ini berupa sebuah aplikasi GIS yang bisa memberikan layanan informasi berbasis web Sistem Informasi Geografis untuk menjelaskan persebaran UKM di daerah Garut. Kesimpulan dari penelitian ini berupa pemafaatan aplikasi system informasi geografis yang dibangun untuk memetakan sebaran UKM perajin tenun yang ada di daerah Garut[2].

Pada penelitian terdahulu "penerapan analytical hierarchy process (AHP) untuk penentuan lokasi optimal cabang baru bisnis otomotif dalam system informasi geografis area marketing" penelitian ini bertujuan untuk menentukan keputusan lokasi cabang baru bagi perusahaan dengan metode analytical hierarchy process (AHP) sebagai penentuan kriteria atau aturan-aturan dalam penambahan cabang baru serta memberikan nilai bobot untuk masing-masing kriteria. Hasil penelitian ini berupa aplikasi SIG berbasis web yang dikembangkan dengan code CSS dan HTML. Untuk antar muka dari SIG area marketing dan juga system penentuan dealer kandidat optimal yang diolah dengan metode analytical hierarchy process (AHP). Kesimpulan dari penelitian ini adalah Sistem Informasi Geografis Area Marketing dapat dibangun dengan memanfaatkan peta digital dari Google Maps, untuk memudahkan membangun SIG, Google Maps memiliki Google Maps API untuk membantu programmer melakukan pengkodean dan pengkonfigurasian Google Maps, dengan metode Analytical Hierarchy Process (AHP) dapat digunakann untuk merangking lokasi kandidat dealer optimal sesuai dengan kriteria-kriteria dan pembobotan kriteria yang ditentukan oleh pengguna[3].

Pada penelitian terdahulu "Pemetaan Platform Media Komunikasi Pemasaran PT. Dyandra Promosindo dalam Ruang Publik di Surabaya" penelitian ini bertujuan untuk mengetahui pemetaan platform media komunikasi pemasaran PT. Dyandra Promosindo dalam ruang publik penyelenggaraan pemeran Indie Clothing Expo 8th. Hasil penelitian ini berupa pemetaan penggunaan elemen periklanan, PT. Dyadra Promosindo yang memanfaatkan berbagai media periklanan sebagai sarana untuk mempromosikan pameran Indie Clothing Expo 8th mulai dari kerjasama promosi dengan beberapa media cetak seperti Koran dan majalah, kemudian beberapa radio lokal, dan akun informative di social media, serta penggunaan media promosi outdoor mulai dari billboard baliho, hingga cutting sticker di angkutan umum. Selain itu, PT. Dyandra Promosindo memaksimalkan penjualan personal melalui program ICE Agent dengan bekerjasama dengan lima puluh perwakilan siswa - siswi SMA se-Surabaya. Dan yang terakhir, penggunaan ticketbox sebagai strategi pemasaran langsung dengan menambahkan program promo untuk meningkatkan pelayananan dan jumlah pengunjung, serta menjaga brand image pameran. Kesimpulan dari penelitian ini berupa pemetaan platform media komunikasi PT. Dyandra Promosindo dalam menciptakan ide-ide baru yang fresh dan kreatif agar mampu mempertahanka brand image serta citra baik yang berkembang dimasyarakat mengenai pameran tersebut[4].

Pada penelitian terdahulu "Sistem Informasi Geografis Bengkel Resmi Mercedes-Benz dan BMW di Kota Jakarta Menggunakan Quantum GIS" penelitian ini bertujuan untuk membantu para pengguna mobil Mercedes-Benz dan BMW untuk menemukan bengkel resmi terdekat secepat mungkin. Hasil penelitian ini berupa aplikasi system informasi geografis yang memberikan kemudahan bagi pengguna mobil Mercendez-Benz dan BMW dalam menemukan bengkel. Kesimpulan dari penelitian ini berupa Sistem Informasi Geografis yang berguna memberi kemudahan bagi pengguna kendaraan pribadi, khususny Mercedes-Benz dan BMW dalam mecari lokasi bengkel resminya[5].

Pada penelitian terdahulu "Pengaruh Strategi Pemasaran Komunitas Terhadap Loyalitas Merek Toyota di Indonesia" penelitian ini bertujuan untuk mengkaji pengaruh strategi pemasaran

JURNAL ILMIAH ELEKTRONIKA DAN KOMPUTER Vol. 14, No. 2, Desember 2021: $350-360$ 
komunitas terhadap loyalitas merk Toyota di indonesia. Hasil penelitian dengan menggunakan structural equation modeling (SEM) menunjukkan bahwa strategi pemasaran komunitas berpengaruh secara signifikan terhadap loyalitas merek Toyota di Indonesia. Kesimpulan dari penelitian ini strategi pemasaran komunitas yang dilakukan oleh ATPM Toyota di Indonesia sudah cukup efektif bagi para komunitas Toyota, pihak ATPM Toyota secara berkesinambungan meningkatkan strategi pemasaran komunitas khususnya pada factor pemberdayaan yang memiliki dampak terbesar pada loyalitas merek[6].

Pada penelitian terdahulu "Analisis Dimensi Strategi Kompetitif dan Pemetaan Strategic Group Produsen Kendaraan Sport Utility Vehicle di Pasar Indonesia" penelitian ini bertujuan untuk memberi gambaran bagaimana pabrikan- pabrikan tersebut akan bertindak terhadap perubahan lingkungan bisnis di masa mendatang berdasarkan berbagai variabel strategik yang ditetapkan saat ini. Hasil penelitian berupa perbandingan strategic beberapa produk yang bisa digunakan sebagai acuan untuk penentuan strategic group. Kesimpulan dari penelitian ini strategic yang lebih baik pada dimesi strategic pelayanan menjadi factor penting penguasaan mereka terhadap pasar. [7].

Pada penelitian terdahulu "Strategi Pemasaran Mobil Merek Daihatsu Pada Dealer Daihatsu Jember" penelitian ini bertujuan untuk mengetahui strategi pemasaran yang digunakan oleh Dealer Daihatsu Jember. Hasil penelitian ini menunjukkan bahwa Dealer Daihatsu Jember berada pada kuadran I yaitu posisi perusahaan yang mendukung strategi agresif. Kesimpulan dari penelitian ini adalah Dealer Daihatsu Jember menggunakan strategi agresif untuk memperluas pasar[8].

Berdasarkan beberapa penelitian terdahulu, maka dalam penelitian ini akan disusun pemetaan wilayah area marketing dealer $\mathrm{X}$ di kabupaten demak untuk peningkatan rencana strategis pemasaran. Penelitian ini menghasilkan output peta untuk memetakan area-area marketing mana saja yang berpotensi pada jumlah penjualan, penunjukan sport-sport yang telah membeli dari dealer $\mathrm{X}$ dalam hal ini wilayah kabupaten demak, persebaran yang belum diagarap oleh team marketing. Dimaksudkan sebagai sumbang saran bagi penyusunan rencana stategis pemasaran pada department pemasaran khususnya dalam hal ini dealer $\mathrm{X}$ yang ada di kabupaten demak.

Pemasaran terdiri dari semua aktivitas yang dirancang untuk menghasilkan dan memfasilitasi setiap pertukaran yang dimaksudkan untuk memuaskan kebutuhan atau keinginan konsumen[9]. Pemasaran, adalah system keseluruhan dari kegiatan usaha yang ditunjukan untuk merencanakan, menentukan harga, mempromosikan dan mendistribusikan barang dan jasa yang dapat memuaskan kebutuhan pembeli yang ada maupun pembeli yang potensial. Pemasaran berarti proses megelola pasar untuk menghasilkan pertukaran dan hubungan dengan tujuan untuk meciptakan nilai serta memuaskan kebutuhan dan keinginan[10].

\section{Metodelogi}

Penelitian ini dilakukan di dealer $X$ di kabupaten demak pada bulan januari sampai dengan maret 2018. Metode penelitian yang digunakan adalah metode klasifikasi spasial yang menggunakan bantuan tools QGis. Metode tersebut terdiri dari tahapan langkah-langkah yaitu:

1. Penentuan jumlah kelas dan jenis kelas (Rumus Sturges)

Untuk menentukan jenis kelas data indikator pemasaran didasarkan pada kriteriakriteria masing-masing data indikator pemasaran, yang mana akan mengakomodasikan aspekaspek variabilitas anggota- anggota kelasnya. Sedangkan untuk menentukan jumlah kelasnya menggunakan rumus Sturges[11].

$\mathrm{K}=1+3,3 \log n$.

Dimana:

$\mathrm{K}=$ jumlah kelas yang dicari

Pemetaan Wilayah Area Marketing Dealer X di Kabupaten Demak untuk Peningkatan Rencana Strategis Pemasaran (Wawan Susanto) 
$\mathrm{N}=$ jumlah set data [12].

Jumlah kelas yang terlalu sedikit (kurang dari 5 kelas) akan menghasilkan peta yang kurang mencerminkan persebaran data asli, karena banyak data yang tergeneralisasi. Sebaliknya bila kelas terlalu banyak (lebih dari 15 kelas) maka akan terjadi beberapa kelas yang sama sekali tidak mengandung frekuensi.

2. Penentuan interval Kelas (Rumus Kingma)

Dalam menentukan Interval Kelas akan menggunakan

Rumus dari Kingma yang bentuknya seperti berikut ini :

$$
\begin{aligned}
& \mathrm{Ki}=\frac{\mathrm{xt}-\mathrm{Xr}}{k} \ldots \ldots \ldots \ldots \ldots \ldots(2) \\
& \text { Keterangan : } \\
& \mathrm{Ki}: \text { Kelas interval Xt : Data Tertinggi Xt : Data Terendah } \\
& \mathrm{k} \quad \text { : Jumlah Kelas yang diinginkan }
\end{aligned}
$$

3. Pembangunan Tabel klasifikasi

Perlu diketahui di sini, bahwa akan digunakan Tabel Eksternal sebagai Tabel Klasifikasi untuk tiap-tiap data indikator marketing. Alat yang digunakan dalam membangun table klasifikasi ini adalah menggunakan Excel, yang nantinya bisa diexport ke aplikasi database agar file dapat berekstensi dbf. Metode yang diterapkan dalam membuat table klasifikasi ini adalah seperti membangun sebuah file data model relasional, yang mana membuat field, tipe data dan kapasitas ukuran untuk item data.

4. Penggabungan table klasifikasi dengan table atribut data spasial

Penggabungan table klasifikasi (table eksternal) dengan

table atribut adalah menggunakan fungsi Join, yang mana dalam hal ini akan memerlukan masingmasing sebuah field yang mempunyai domain yang sama diantara dua table sebagai media penggabung.

5. Proses pemodelan spasial baru

Pemodelan spasial baru menggunakan bantuan tools Quantum Gis (QGis) sebagai alat bantu untuk memetakanya.

\section{FLOWCHART OF DIAGRAM SYSTEM}

System flowchart merupakan diagram alir yang menggambarkan suatu system logika computer yang digunakan untuk proses pengolahan data serta hubungan antar peralatan tersebut[13]. Dalam peningkatan recana strategis pemasaran yang efisiensi dan efektifitas pada pemasaran dealer $\mathrm{X}$ demak maka diusulkannya system baru dengan flowchart sebagai berikut :

JURNAL ILMIAH ELEKTRONIKA DAN KOMPUTER Vol. 14, No. 2, Desember 2021: $350-360$ 
Fowchart Pelaksanaan Studi Kasus

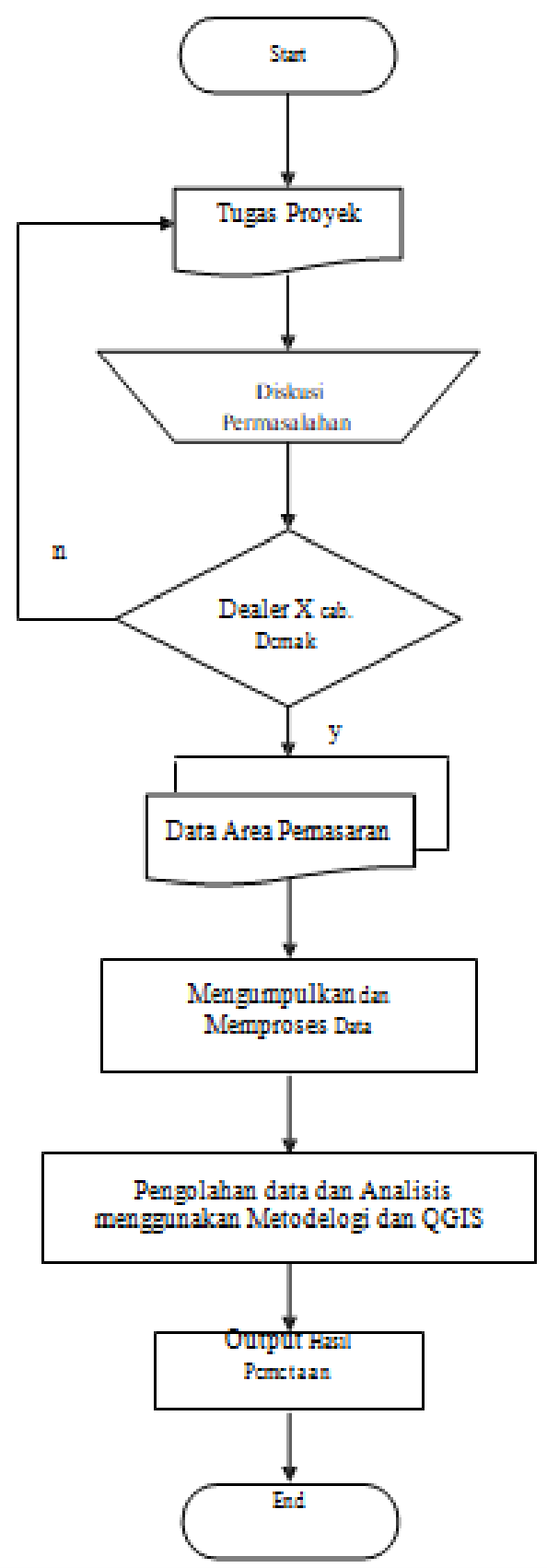

Gambar 1.1 flowchart model

Gambar tersebut adalah rangkaian dari kegiatan penelitian ini dalam pemetaan di dealer $\mathrm{X}$ cabang demak. selanjutnya penelitian ini membahas tentang proyek yang akan diselesaikan. Yang sebelumnya sudah ditentukan target dealer mana yang akan dijadikan tempat penelitian. Dari diskusi tersebut menghasilkan perusahaan yang dijadikan tempat penelitian adalah Dealer X cabang Demak.

Pemetaan Wilayah Area Marketing Dealer X di Kabupaten Demak untuk Peningkatan Rencana Strategis Pemasaran (Wawan Susanto) 
Flowchart Pemetaan Area Pemasaran

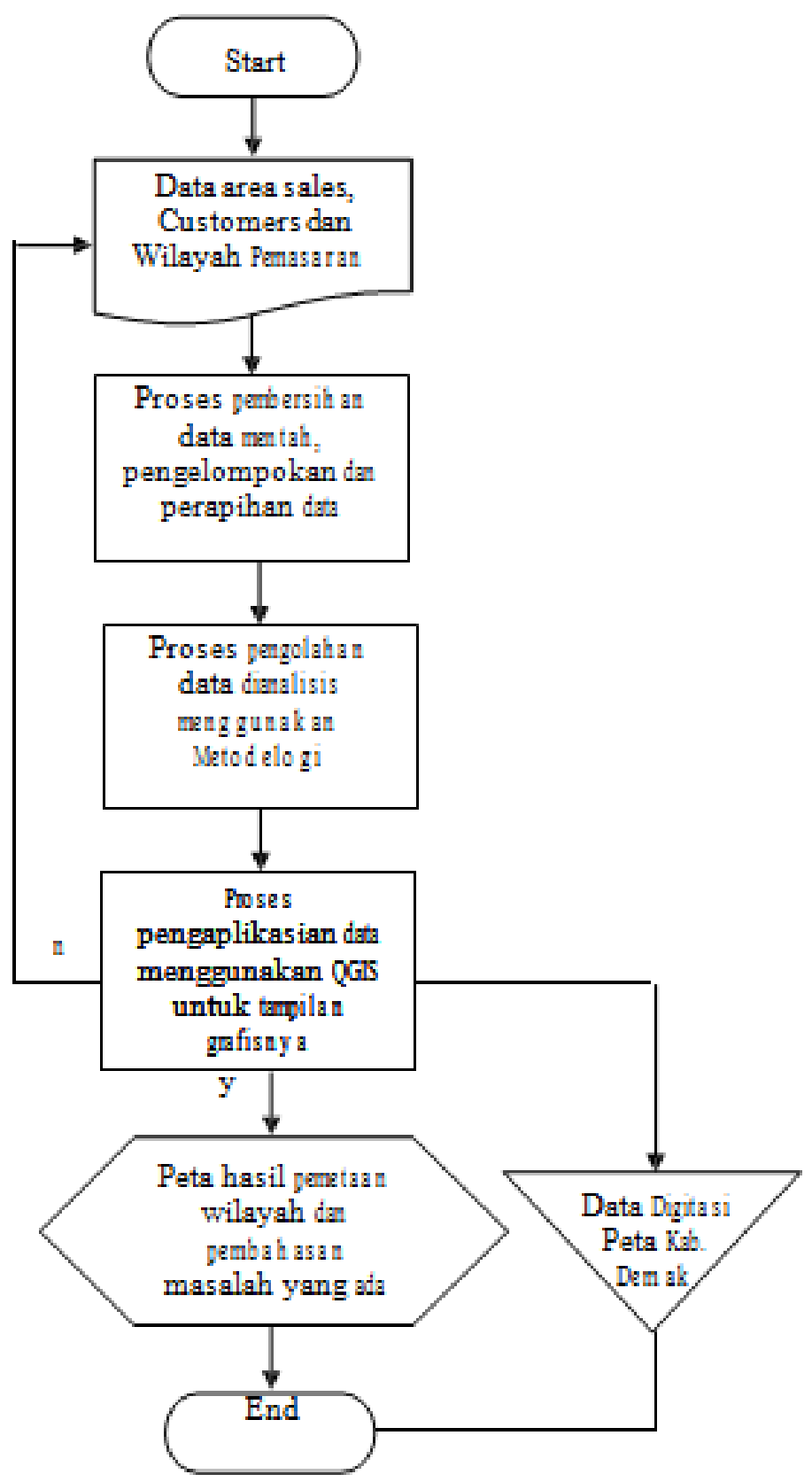

Gambar 1.2 flowchart perancangan pemetaan

Gambar diatas berawal dari inputan data - data pemasaram data dari dealer X cabang demak. kemudian di proses berdasarkan area perwilyah. Selanjutnya data dianalisis menggunakan metodelogi yang telah diambil kemudian diaplikasikan menggunakan tool QGis untuk proses pemetaan. Sehingga menghasilkan data digitasi pada daerah kabupaten demak.

JURNAL ILMIAH ELEKTRONIKA DAN KOMPUTER Vol. 14, No. 2, Desember $2021: 350-360$ 


\section{Hasil dan Analisa}

Data yang disuguhkan berupa :

1. Grafik Data Digitasi Peta Kabupaten Demak

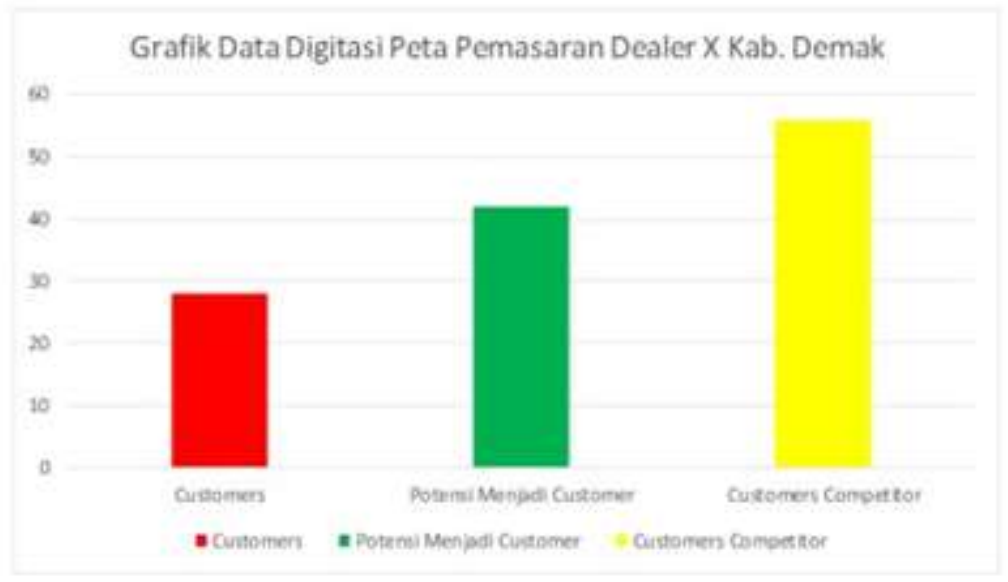

2. Grafik Data peta yang dari gambar dirubah menjadi digital (digitasi) menggunakan tools QGis.

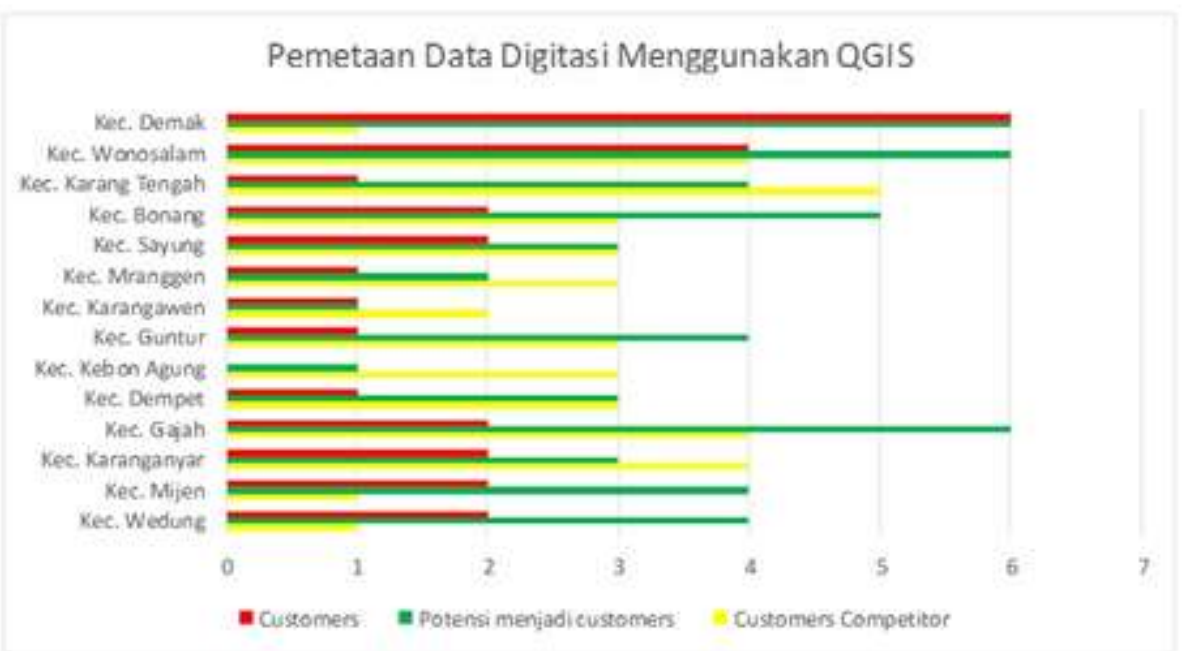

3. Data sales area Dealer X cabang demak

\begin{tabular}{|l|l|}
\hline Nama & Area \\
\hline Sofian Arafat & Mranggen \\
\hline Aji & Wedung \\
\hline Anam & Sayung \\
\hline Anjas & Karangawen \\
\hline Iskak & Bonang \\
\hline
\end{tabular}

Pemetaan Wilayah Area Marketing Dealer X di Kabupaten Demak untuk Peningkatan Rencana Strategis Pemasaran (Wawan Susanto) 


\begin{tabular}{|l|l|}
\hline Latif & Gajah \\
\hline Arief & Karang Tengah \\
\hline Artiko & Mijen \\
\hline Yusuf & Demak \\
\hline Tomi & Kebon Agung \\
\hline Ulin & Karang Anyar \\
\hline Budi & Dempet \\
\hline Adit & Guntur \\
\hline Haikal & Wonosalam \\
\hline
\end{tabular}

4. Data Profil para sales Dealer X cabang Demak

\begin{tabular}{|l|l|l|l|}
\hline Nama & Lulusan & No. Hp & Alamat \\
\hline Sofian Arafat & SMA & 081225292625 & Jl. Raya Mranggen No. 173 Mranggen \\
\hline Aji & S1 & 082136515154 & Jl. Ngawen,wedung, kab. Demak \\
\hline Anam & D3 & 082227552555 & Jl. Purwosari, sayung, demak \\
\hline Anjas & S1 & 082135739824 & $\begin{array}{l}\text { Jl. Raya Karangawen, no. 115, punden arum, } \\
\text { karangawen }\end{array}$ \\
\hline Iskak & D3 & 085293204060 & Jl. Raya bonang, demak, trindonorejo, bonang \\
\hline Latif & D3 & 081225677477 & Jl. Gajah-geneng no. 41, kec.gajah,kab. Demak \\
\hline Arief & D3 & 081391851955 & Jl. Buyaran, karangtengah, kab. Demak \\
\hline Artiko & S1 & 085640310509 & Jl. Raya mijen jleper, kec. Mijen, kab. Demak \\
\hline Yusuf & D3 & 081283303034 & Jl. Sultan fatah no.16 bintoro, demak \\
\hline Tomi & S1 & 082227763541 & Jl. Semarang-Purwodadi km. 30 no.21 demak \\
\hline Ulin & S1 & 085876155209 & Jl. Wonorejo, karanganyar, demak \\
\hline Budi & D3 & 089667110220 & Jl. Kauman dempet km. 10 kec. Dempet \\
\hline Adit & S1 & 085640486282 & Jl. Guntur raya no. 12, kec Guntur, demak \\
\hline Haikal & S1 & 081225616168 & Sawah Besar V, kaligawe, semarang \\
\hline
\end{tabular}

Layout Digitasi Pemetaan

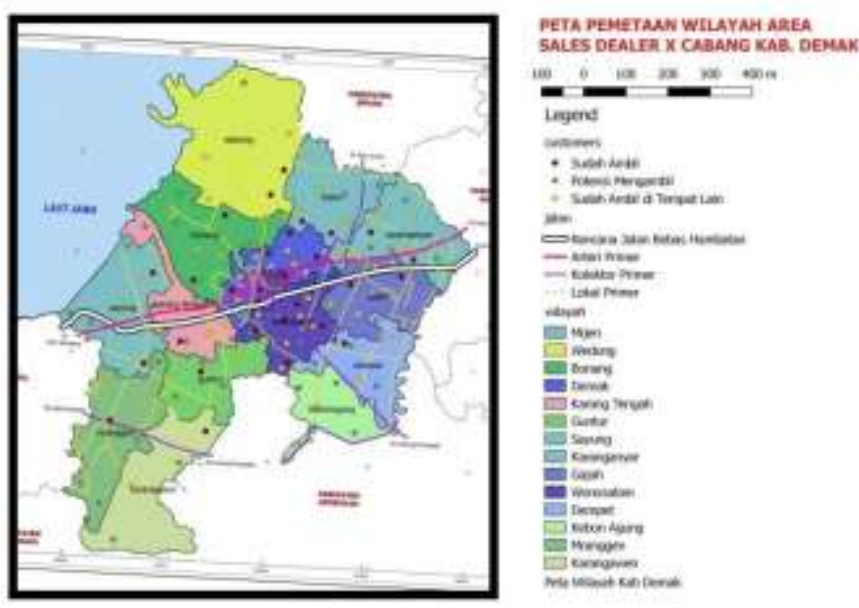

Gambar 1.3 layout peta legenda

JURNAL ILMIAH ELEKTRONIKA DAN KOMPUTER Vol. 14, No. 2, Desember $2021: 350-360$ 
Layout pemetaan perwilayah

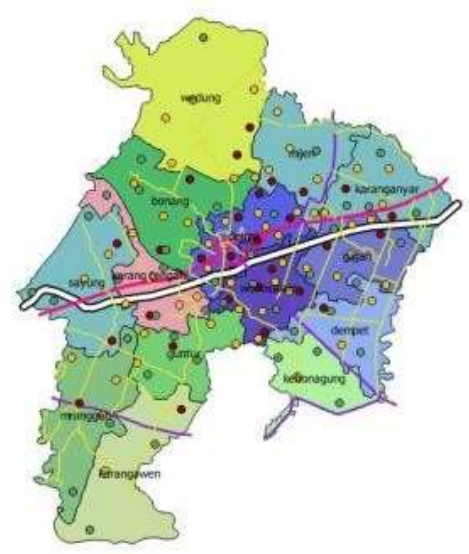

Gambar 1.4 peta perwilayah

Gambar tersebut menunjukkan titik-titik yang menjadi area dari sales dealer $\mathrm{X}$ di wilayah kabupaten demak. titik tersebut mewakili setiap customer yang menjadi area pemasaran di wilayah kabupaten demak.

Titik merah menjelaskan high yang berarti banyak customer dealer X yang terdapat pada titik tersebut. Titik hijau menjelaskan calon customer yang berarti potensi akan menjadi customer dealer X yang terdapat pata titik tersebut. Dan untuk titik kuning menjelaskan customer yang belum membeli pada dealer $\mathrm{X}$ demak atau sudah menjadi customer dealer ataupun pemakai produk lainnya.

\section{Kesimpulan}

Berdasarkan penelitian yang telah di susun maka penulis dapat menarik kesimpulan dengan adanya penelitian pada studi kasus ini khususnya wilayah dealer X cabang demak, dapat lebih mudah dalam memahami data-data persebaran area pemasaran di wilayah tersebut. Pembagian data-data dan informasi berdasarkan persebaran area kerja sales menjadi lebih akurat. Bisa dijadikan untuk pertimbangan bagian department pemasaran sebagai upaya peningkatan rencana startegis pemasaran

\section{Daftar Pustaka}

[1] Fajar, Rahmad, Noermijati, Mintarti Rahayu, Mohammad Fatchi, 2012,. "Model Sales Territory Management "Cluster War" Sebagai Bentuk Strategi Pemasaran Pada PT. Telkomsel Sub Branch Malang”, Jurnal Ilmiah Mahasiswa Fakultas Ekonomi dan Bisnis, Vol 1, No 1.

Pemetaan Wilayah Area Marketing Dealer X di Kabupaten Demak untuk Peningkatan Rencana Strategis Pemasaran (Wawan Susanto) 
[2] Wulandari, Maria Sri, Rahayu Noveandini, Sutarno, 2015,. "Digitalisasi Pemetaan UKM Tenun Garut Berbasis Sistem Informasi Geografis Sebagai Media Komunikasi dan Pemasaran Produk Lokal", Prosiding Seminar Nasional Multi Disiplin Ilmu \& Call For Papers Unisbank (SENDI_U), ISBN: 978-979-36-49-81-8.

[3] Pradharma, Putu Agni, Ida Bagus Gede Dwidasmara, 2012,. "Penerapan Analytical Hierarchy Process (AHP) Untuk Penentuan Lokasi Optimal Cabang Baru Bisnis Otomotif Dalam Sistem Informasi Geografis Area Marketing", Jurnal Elektronik Ilmu Komputer Universitas Udayana, Volume 1, No. 1.

[4] Putra, Bayu Pratama, Iwan Joko Prasetyo, 2017,. "Pemetaan Platform Media Komunikasi Pemasaran PT. Dyandra Promosindo dalam Ruang Publik di Surabaya", Jurnal Komunikasi Profesional, Vol 1, No 2.

[5] Rahayu, Agustini Dwi Setia, Ana Rizki, Ria Awalliya, 2012,. "Sistem Informasi Geografis Bengkel Resmi Mercedes-Benz dan BMW di Kota Jakarta Menggunakan Quantum GIS", Prosiding KOMMIT 2012, Vol 7, ISSN : 2302-3740.

[6] Aditya Wardana, 2016,. "Pengaruh Strategi Pemasaran Komunitas Terhadap Loyalitas Merek Toyota di Indonesia", Jurnal Manajemen, Vol. 11, No. 2.

[7] Prarendra, Irfan, Peggy Hariwan, 2014, "Analisis Dimensi Strategi Kompetitif dan Pemetaan Strategic Group Produsen Kendaraan Sport Utility Vehicle di Pasar Indonesia”, Jurnal Manajemen Bisnis Indonesia, Vol. 1, Nomor 3.

[8] Untari, Shinta Nurafni, Sutrisno Djaja, Joko Widodo, 2017, "Strategi Pemasaran Mobil Merek Daihatsu Pada Dealer Daihatsu Jember", Jurnal Ilmiah Ilmu Pendidikan, Ilmu Ekonomi, dan Ilmu Sosial, ISSN 1907- 9990 | E-ISSN 2548-7175 | Volume 11 Nomor 2.

[9] Kotler, Philip.2005.Dasar-dasar Pemasaran.Erlangga.Jakarta.

[10] Swastha, Basu.2007.Manajemen Pemasaran Modern.Liberty.Jakarta.

[11] Sturges, H.A, 1926, "The Choice of a Class Interval", Jurnal of The American Statistical Association. 21, 65-66.

[12] Bos, E.S., 1979, "Thematic Cartography. Faculty of Geography. Gadjah Mada University. Yogyakarta, Indonesia.

[13] Turban, Efrain, 2009, Decision Support System and Intelligent System, Penerbit Andi,Yogyakarta.

JURNAL ILMIAH ELEKTRONIKA DAN KOMPUTER Vol. 14, No. 2, Desember 2021: $350-360$ 